\title{
Factors associated with the success of intracytoplasmic sperm injection for the treatment of conjugal infertility
}

\author{
Rodrigo Dias Nunes ${ }^{1,2 *}$, Tássia Beatriz Freiberger Vieira', Jefferson Traebert ${ }^{2}$ \\ 'Universidade do Sul de Santa Catarina (UNISUL), School of Medicine, Palhoça, SC, Brasil \\ 2Universidade do Sul de Santa Catarina (UNISUL), Post-Graduate Program in Health Sciences, Palhoça, SC, Brasil
}

\begin{abstract}
Objectives: Obtaining and maintaining pregnancy after intracytoplasmic sperm injection (ICSI) may be affected by many technical factors. The goal of this study is to determine the rates of success from ICSI technique with established parameters and assess the associated factors to its success to treat infertility. Methods: A cross-sectional study involving 115 infertile couples submitted to ICSI was performed to test the association between technical aspects and success rates, from July 2013 to December 2014. Data collection was done through medical records. The bivariate associations were calculated by prevalence ratios and a Poisson regression was performed with significance level $p<0.05$. Results: The aspiration of eight or more oocytes was 0.73 times (Cl 95\% 0.57-0.94) less associated $(p=0.014)$, but transferring two or more embryos was 1.75 times (CI 95\% 1.54-1.99) more associated with the viable pregnancy $(p<0.001)$. The remaining characteristics of the ICSI procedures were not significantly associated with the expected outcome. Conclusions: The prevalence of the viable pregnancy after ICSI procedure was $40.9 \%$. This index was positively influenced by the aspiration of less than eight oocytes and the transferring of two or more embryos.
\end{abstract}

Keywords: infertility; pregnancy rate; sperm injections, intracytoplasmic.

\section{Introduction}

Infertility is defined as the inability of a sexually active couple, without the use of contraceptive methods, to achieve pregnancy within a year, during which, approximately, $90 \%$ of couples do. It is a relatively common phenomenon, which affects around 8 to $15 \%$ of couples, regardless of socioeconomic or cultural factors. ${ }^{1}$

The fact that many couples do not achieve pregnancy is one of the major causes of crisis in their lives. It can cause depression, anxiety, social isolation and even sexual dysfunction. Thus, many infertile couples seek medical help for assisted reproduction treatments. According to the condition of the patient, the majority is subjected to in vitro fertilization (IVF) or intracytoplasmic sperm injection (ICSI). ${ }^{2}$

These treatments include testing and monitoring ovulation and semen parameters, medical support to conception and assisted reproductive technology (ART). ${ }^{3}$ Since 1978, more than one million children born through these procedures around the world. Currently, ART is available worldwide and has been successfully practiced on a large scale. About one to four per cent of all live births in Europe resulted from IVF or ICSI. In these techniques fertilization occurs outside of the reproductive system, in which both sperm and oocyte are handled. ${ }^{4}$

The source of the problem can be found in both members of the couple. Male factor can represent up to $50 \%$ of infertility causes and azoospermia (total absence of sperms) is present in $5 \%$ of all investigated infertile couples, and it is found in $10 \%$ of couples with male infertility. ${ }^{5}$

With the development of ICSI in 1992, a new treatment option has become available for male infertility, since the technique can be successfully used even for the most severe cases of oligoasthenoteratospermia (OAT) or azoospermia. ${ }^{6}$

\footnotetext{
Financial support: None.

Conflicts of interest: The authors declare no conflicts of interest.

Submitted: Jan. 29, 2018.

Accepted: Set. 16, 2019.

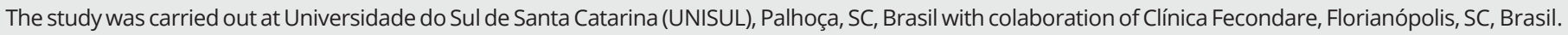

Copyright Nunes et al. This is an Open Access article distributed under the terms of the Creative Commons Attribution License, which permits unrestricted use, distribution, and reproduction in any medium, provided the original work is properly cited.
} 
Furthermore, a selected sperm with morphologically straight intermediate parts, contributes to the enhanced expression of the centrosome function, providing a positive effect on fertilization with ICSI. ${ }^{7}$

ICSI, throughout the world, achieves a success rate of 25 to $30 \%$ of pregnancies. ${ }^{8}$ It is nowadays an established and indispensable technique in assisted reproduction programs, allowing paternity even for men with very poor-quality sperm. It can be proceeded with thawed sperm or those semen with abnormal sperm concentration, motility or morphology. It can even be handled with sperm surgically recovered from the epididymis or testicle. ${ }^{9}$ However, some factors may influence these rates directly or indirectly and in a beneficial or harmful way. ${ }^{10}$

Obtaining and maintaining pregnancy after ICSI may be affected by women obesity, with lower chances of becoming pregnant and a greater chance of miscarriage after treatment. ${ }^{11}$ However, in a ICSI procedure, the probability of clinical pregnancy does not decrease if the male partner is overweight, unlike traditional IVF. The sperm concentration may be negatively influenced by alcohol and positively influenced by the consumption of cereals and number of meals per day. ${ }^{7}$

Age is also an unfavorable indicator in treatment, as well as endometriosis, previous pelvic surgery and polycystic ovary syndrome, present as poor ovarian response predictors. Above all, heredity plays an important role (Gong et al., 2015). But, moreover, the implantation and clinical pregnancy rates appear to be significantly correlated with the endometrium thickness. $^{12}$

Interestingly, couples undergoing ICSI procedure can ensure that anxiety and depression levels, before and during treatment, has no considerable influence on success rates. ${ }^{13}$

These advantages highlight the importance of ICSI among other assisted reproductive technologies and make it often to be the method of choice for many infertile couples who crave children. Therefore, ICSI success indicators include processing (number and quality of retrieved, inseminated and fertilized oocytes) and outcome measures (pregnancy rates, abortions and live births). ${ }^{5}$

The goal of this study is to determine the rates of success from ICSI technique with established parameters and assess the associated factors to its success to treat infertility in a private service. Such responses would help to analyze how these data can interfere before, during or after assisted reproduction, allowing better guidance to couples looking for this type of care.

\section{Methods}

A cross-sectional study was performed to test the association between technical aspects regarding ICSI and success rates obtained from this ART. All records of couples submitted to ICSI procedure at Fecondare, a specialized clinic in infertility, located in the city of Florianópolis, Brazil, from July 2013 to December 2014, were included. No medical record was excluded.

After medical record analysis, it was noted that 115 couples were conducted to ICSI. The technical factors considered to be compared to pregnancy rates were patients' ages, collection day according to the menstrual cycle, method for semen's acquisition, number of aspirated oocytes, number of cells at the transferred embryo, transfer day and number of transferred embryos. Viable pregnancies (gestational age $\geq 24$ weeks) were considered as outcome.

Statistical analysis was performed using software SPSS 18.0. The qualitative variables were described in absolute and relative frequencies, and quantitative variables were categorized for further bivariate analysis. The chi-square was used to test the homogeneity between variables with significance level $p<0.05$. Prevalence ratios (PR) and their respective $95 \%$ confidence intervals were estimated. Considering the existence of possible confounding characteristics, the Poisson regression analysis was performed among variables with $p<0.25$. This study was approved by Ethics Committee on Human Research under CAA number 12.428.4.01.III.

\section{Results}

Considering the 115 couples treated with ICSI, the prevalence of viable pregnancies after ICSI procedure was $40.9 \%$. The mean age was $36.5 \pm 2.6$ years old, with extremes ranging from 25 to 48 years. Among women, the age ranged from 25 to 42 years, with a mean of $32.3 \pm 2.9$ years; while the mean age of men was $38.3 \pm 4.5$ years, and it varied from 35 to 52 years old. All couples were white and lived together.

The oocytes collection varied from the 10th to the 19th day of the menstrual cycle. The number of aspirated oocytes ranged from three to 26 , and the number of oocytes which received the sperm injection varied from two to 13 . The injected embryos contained from 4 to 64 cells, the transfer day varied between the 2nd and the 5th day of fertilization, and 2 to 4 embryos were transferred to each woman. The characteristics of the ICSI procedure are categorized and visualized in Table 1.

The multivariate analysis demonstrated that the aspiration of eight or more oocytes was 0.73 times (CI 95\% 0.57-0.94) less associated with the viable pregnancy $(p=0.014)$. But, transferring two or more embryos was 1.75 times (CI 95\% 1.54-1.99) more associated with the viable pregnancy $(p<0.001)$. The remaining characteristics of the ICSI procedures were not significantly associated with the expected outcome. The results of the bivariate and multivariate analysis are demonstrated in Table 2 . 
Table 1. Comparative analysis between the characteristics of the ICSI procedure in infertile couples and the success rate determinate by a viable pregnancy. 2016. $(n=115)$

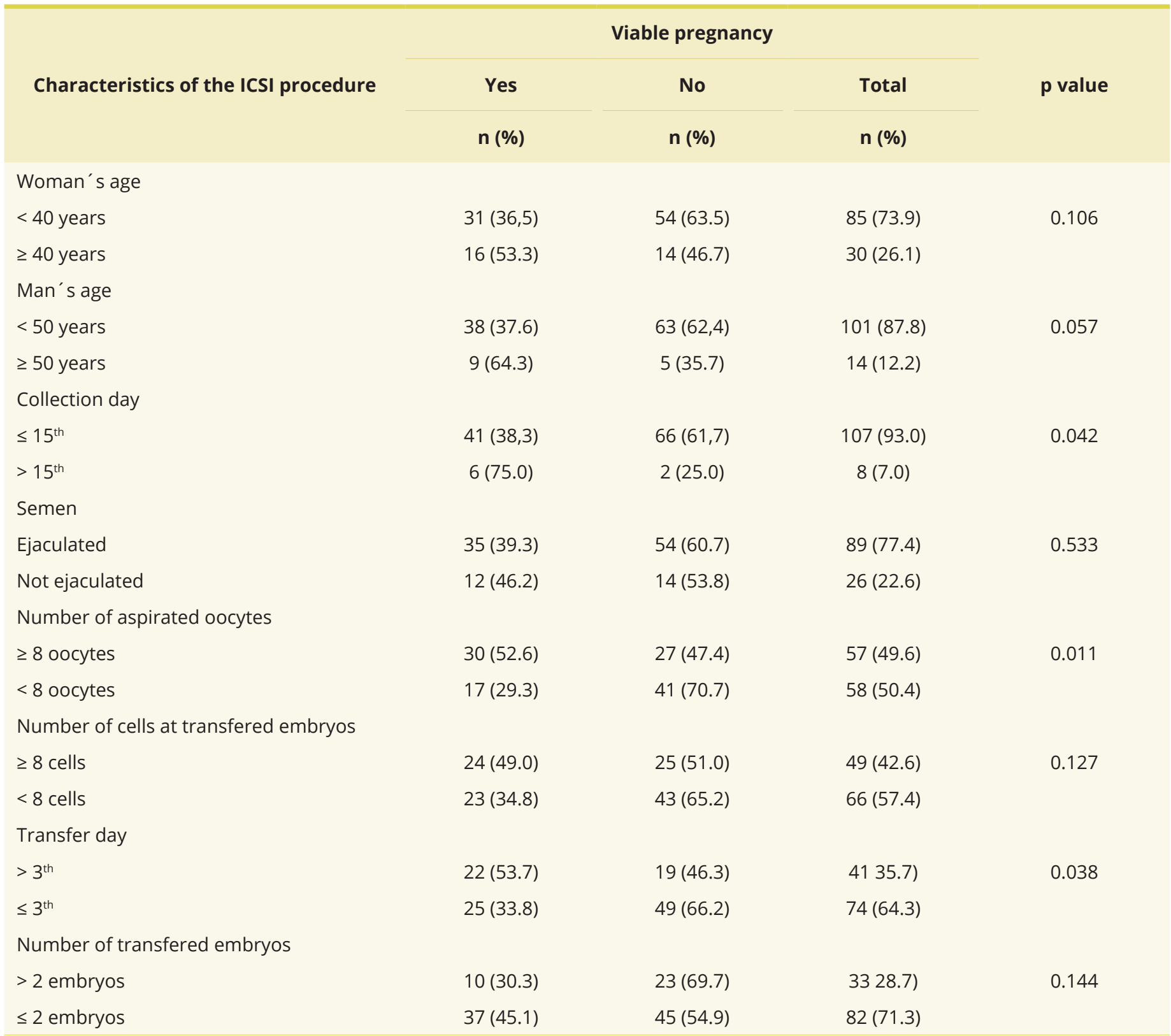

Table 2. Bivariate and multivariate analysis between the characteristics of ICSI procedure in infertile couples and the success rate determinate by a viable pregnancy. 2016. $(n=115)$

\begin{tabular}{|c|c|c|c|c|}
\hline \multirow{2}{*}{ Characteristics of the ICSI procedure } & \multicolumn{4}{|c|}{ Viable pregnancy } \\
\hline & $\mathrm{PR}_{\mathrm{b}}(\mathrm{Cl}$ 95\%) & p value & $\mathrm{PR}_{\mathrm{a}}(\mathrm{Cl}$ 95\%) & p value \\
\hline Woman's age & $0.68(0.44-1.06)$ & 0.106 & $1.02(0.94-1.11)$ & 0.646 \\
\hline$<40$ years & 1.00 & & 1.00 & \\
\hline
\end{tabular}

$\mathrm{PR}_{\mathrm{b}}$ : crute prevalence ratio; $\mathrm{PR}_{\mathrm{a}}$ : adjusted prevalence ratio by Poisson regression. 
Table 2. Continued...

\begin{tabular}{|c|c|c|c|c|}
\hline \multirow{2}{*}{ Characteristics of the ICSI procedure } & \multicolumn{4}{|c|}{ Viable pregnancy } \\
\hline & $\mathrm{PR}_{\mathrm{b}}(\mathrm{Cl}$ 95\%) & p value & $\mathrm{PR}_{\mathrm{a}}(\mathrm{Cl} 95 \%)$ & $p$ value \\
\hline Man's age & $0.59(0.37-0.93)$ & 0.057 & $1.24(0.94-1.65)$ & 0.134 \\
\hline$<50$ years & 1.00 & & 1.00 & \\
\hline \multicolumn{5}{|l|}{$\geq 50$ years } \\
\hline Collection day & $0.51(0.32-0.82)$ & 0.042 & $1.20(0.84-1.72)$ & 0.319 \\
\hline$\leq 15^{\text {th }}$ & 1.00 & & 1.00 & \\
\hline \multicolumn{5}{|l|}{$>15^{\text {th }}$} \\
\hline Semen & $0.85(0.52-1.39)$ & 0.533 & $\#$ & \\
\hline Ejaculated & 1.00 & & & \\
\hline \multicolumn{5}{|l|}{ Not ejaculated } \\
\hline Number of aspirated oocytes & $1.80(1.12-2.87)$ & 0.011 & $0.73(0.57-0.94)$ & 0.014 \\
\hline$\geq 8$ oocytes & 1.00 & & 1.00 & \\
\hline \multicolumn{5}{|l|}{$<8$ oocytes } \\
\hline Number of cells at transfered embryos & $1.41(0.91-2.18)$ & 0.127 & $1.02(0.73-1.43)$ & 0.912 \\
\hline$\geq 8$ cells & 1.00 & & 1.00 & \\
\hline \multicolumn{5}{|l|}{$<8$ cells } \\
\hline Transfer day & $1.59(1.04-2.44)$ & 0.038 & $0.85(0.72-1.02)$ & 0.073 \\
\hline$>3^{\text {th }}$ & 1.00 & & 1.00 & \\
\hline \multicolumn{5}{|l|}{$\leq 3^{\text {th }}$} \\
\hline Number of transfered embryos & $0.67(0.38-1.19)$ & 0.144 & $1.75(1.54-1.99)$ & $<0.001$ \\
\hline$>2$ embryos & 1.00 & & 1.00 & \\
\hline$\leq 2$ embryos & & & & \\
\hline
\end{tabular}

$\mathrm{PR}_{\mathrm{b}}$ : crute prevalence ratio; $\mathrm{PR}_{\mathrm{a}}$ : adjusted prevalence ratio by Poisson regression.

\section{Discussion}

Some authors affirm that age is the most important predictor of success of ART. It seems that the reproductive function in both men and women declines with time. ${ }^{14}$ However, this study showed no evidence of the effects of maternal and paternal age on outcome, as sustained by other authors. ${ }^{15}$ It was demonstrated that despite the age increasing has a negative influence on the number of high quality embryos, there was no effect on the results of pregnancies in couples undergoing ICSI.

The day of collection did not interfere with the outcomes. But, probably because this collection was performed around the standard phase, near the 14th day, when the ovulation was confirmed.

The results could infer that ICSI procedure could be performed by two types of sperm acquisition, ejaculated or not ejaculated, without interfering in the rates of viable pregnancies.

However, some authors showed conflicting results about the issue. ${ }^{16}$

In this study, almost $2 / 3$ of viable pregnancies happened in women who had more than eight oocytes retrieved. According to some authors, ${ }_{17}^{17}$ the live births rate significantly increases with the number of retrieved oocytes. Good responders with more than 15 oocytes retrieved, also showed a significantly higher rate compared to poor responders (0-3 oocytes) and suboptimal responders (4-9 oocytes). But this study has shown better results in suboptimal responders when compared to those with normal ovarian response. However, it was described that there was no advantage in getting more than ten oocytes during retrieval, compared to six-to-eight oocytes. ${ }^{18}$ In an Australian analysis ${ }^{19}$ it was 
demonstrated rates of clinical pregnancies and live births, per embryo transferred, of $9.2 \%$ with one oocyte collected, the $37.7 \%$ when more than 16 oocytes were collected.

The authors also affirmed that not always a greater number of oocytes promotes better results. They suggested that if more than 15 oocytes were collected, the success rates would drop. In addition, the patient has a lower risk of complications and better chances of pregnancy when the embryo comes from only one oocyte previously collected.

Probably, the selection of embryos is the most valuable tool to improve implantation rates in an ART cycle. A variety of morphological criteria are analyzed, as the number of blastomeres, fragmentation and symmetry aspect of the zona pellucida, etc. ${ }^{20}$ According to an Indian study, ${ }^{21}$ the clinical pregnancy after transfer of oocytes at blastocyst stage were significantly higher, when compared to oocytes in cleavage stages. Also, they concluded that the transfer of blastocysts resulted in higher rates of implantation and clinical pregnancy, in addition to reducing the chance of multiple pregnancies. In the present study, only $14.9 \%$ of pregnancies became from oocytes in blastocyst stage. It shows that mature oocytes at the time of collection and closer to the blastocyst stage increased the fertilization rates and, consequently, the viable pregnancies.

Considering the day of transferring, it was demonstrated that taking the embryo culture until day five allowed the chromosomally competent embryo to develop until the blastocyst stage, and improved the physiologic synchronization with the endometrium, resulting in better rates. It allows to transfer fewer embryos, but with better quality. However, these results presented $53.2 \%$ of pregnancies occurred after embryo transfer until the 3rd day. In a Spanish research, the authors 22 reached a different conclusion, as the embryo transfers made on the 6th day resulted in significantly higher pregnancy and implantation rates, when compared to the 3rd. And, there was no significant difference between the 2 nd and 3rd day.

The present study showed that $78.7 \%$ of the viable pregnancies occurred with no more than two embryos transferred. The data analysis from several countries demonstrated that $46.9 \%$ of the total number of TRA transferred only two embryos. ${ }^{23}$ Another study detected that transferring a single embryo was associated with lower rate of live births than the transfer of two embryos. ${ }^{15}$ The results of this study were like those found in literature and reinforced the theory that the ideal number of embryos transferred is at most two.

It was possible to conclude that the prevalence of the viable pregnancy after ICSI procedure was $40.9 \%$. This index was positively influenced by the aspiration of less than eight oocytes and the transferring of two or more embryos. The other characteristics of the ICSI procedure were not associated to the expected outcome.

\section{References}

1. Pasqualotto FF. Investigation and assisted reproduction in the treatment of male infertility. Rev Bras Ginecol Obstet. 2007;29(2):10312. http://dx.doi.org/10.1590/S0100-72032007000200008.

2. Rashidi B, Montazeri A, Ramezanzadeh F, Shariat M, Abedinia N, Ashrafi M. Health-related quality of life in infertile couples receiving IVF or ICSI treatment. BMC Health Serv Res. 2008;8(1):186. http://dx.doi.org/10.1186/1472-6963-8-186. PMid:18803838.

3. Marino JL, Moore VM, Rumbold AR, Davies MJ. Fertility treatments and the young women who use them: an Australian cohort study. Hum Reprod. 2011;26(2):473-9. http://dx.doi.org/10.1093/humrep/deq305. PMid:21071491.

4. Jin R, Bao J, Tang D, Liu F, Wang G, Zhao Y, et al. Outcomes of intracytoplasmic sperm injection using the zona pellucida-bound sperm or manually selected sperm. J Assist Reprod Genet. 2016;33(5):597-601. http://dx.doi.org/10.1007/s10815-016-0676-6. PMid:26941098.

5. Ashrafi M, Madani T, Movahedi M, Arabipoor A, Karimian L, Mirzaagha E, et al. Increasing the number of embryos transferred from two to three, does not increase pregnancy rates in good prognosis patients. Int J Fertil Steril. 2015;9(3):292-9. PMid:26644851.

6. Povlsen BB, Aw LD, Laursen RJ, Esteves SC, Humaidan P. Pregnancy and birth after intracytoplasmic sperm injection with normal testicular spermatozoa in a patient with azoospermia and tail stump epididymal sperm. Int Braz J Urol. 2015;41(6):1220-5. http:// dx.doi.org/10.1590/S1677-5538.IBJU.2015.0296. PMid:26742983.

7. Ugajin T, Terada Y, Hasegawa H, Nabeshima H, Suzuki K, Yaegashi N. The shape of the sperm midpiece in intracytoplasmic morphologically selected sperm injection relates sperm centrosomal function. J Assist Reprod Genet. 2010;27(2-3):75-81. http:// dx.doi.org/10.1007/s10815-009-9371-1. PMid:20012684.

8. Maiburg M, Alizadeh B, Kastrop P, Lock M, Lans S, Giltay J. Does the genetic and familial background of males undertaking ICSI affect the outcome? J Assist Reprod Genet. 2009;26(6):297-303. http://dx.doi.org/10.1007/s10815-009-9315-9. PMid:19548080.

9. Hajder M, Hajder E, Husic A. The effects of total motile sperm count on spontaneous pregnancy rate and pregnancy after IUI treatment in couples with male factor and unexplained infertility. Med Arh. 2016;70(1):39-43. http://dx.doi.org/10.5455/ medarh.2016.70.39-43. PMid:26980930.

10. Jawed S, Rehman R, Ali MA, Abdullah UH, Gul H. Fertilization rate and its determinants in intracytoplasmic sperm injection. Pak J Med Sci. 2016;32(1):3-7. PMid:27022334. 
11. Braga DP, Halpern G, Figueira RC, Setti AS, laconelli AJ Jr, Borges EJ Jr. Food intake and social habits in male patients and its relationship to intracytoplasmic sperm injection outcomes. Fertil Steril. 2012;98(1):53-9. http://dx.doi.org/10.1016/j.fertnstert.2011.10.011. PMid:22078783.

12. Ghuman NK, Mair E, Pearce K, Choudhary M. Does age of the sperm donor influence live birth outcome in assisted reproduction? Hum Reprod. 2016;31(3):582-90. http://dx.doi.org/10.1093/humrep/dev331. PMid:26762315.

13. Lampe A, Schüßler G. Psychosocial factors in reproductive medicine. Z Psychosom Med Psychother. 2015;61(4):309-26. http:// dx.doi.org/10.13109/zptm.2015.61.4.309. PMid:26646911.

14. Lahav-Baratz S, Koifman M, Shiloh H, Ishai D, Wiener-Megnazi Z, Dirnfeld M. Analyzing factors affecting the success rate of frozen-thawed embryos. J Assist Reprod Genet. 2003;20(11):444-8. http://dx.doi.org/10.1023/B:JARG.0000006705.46147.a2. PMid:14714822.

15. Pandian Z, Marjoribanks J, Ozturk O, Serour G, Bhattacharya S. Number of embryos for transfer following in vitro fertilisation or intra-cytoplasmic sperm injection. Cochrane Database Syst Rev. 2013;(7):CD003416. http://dx.doi.org/10.1002/14651858. CD003416.pub4. PMid:23897513.

16. Pabuccu EG, Caglar GS, Tangal S, Haliloglu AH, Pabuccu R. Testicular versus ejaculated spermatozoa in ICSI cycles of normozoospermic men with high sperm DNA fragmentation and previous ART failures. Andrologia. 2017;49(2):e12609. http://dx.doi.org/10.1111/ and.12609. PMid:27108915.

17. Drakopoulos P, Blockeel C, Stoop D, Camus M, de Vos M, Tournaye H, et al. Conventional ovarian stimulation and single embryo transfer for IVF/ICSI. How many oocytes do we need to maximize cumulative live birth rates after utilization of all fresh and frozen embryos? Hum Reprod. 2016;31(2):370-6. http://dx.doi.org/10.1093/humrep/dev316. PMid:26724797.

18. McAvey B, Zapantis A, Jindal SK, Lieman HJ, Polotsky AJ. How many eggs are needed to produce an assisted reproductive technology baby: is more always better? Fertil Steril. 2011;96(2):332-335. http://dx.doi.org/10.1016/j.fertnstert.2011.05.099. PMid:21718991.

19. Briggs R, Kovacs G, MacLachlan V, Motteram C, Baker HW. Can you ever collect too many oocytes? Hum Reprod. 2015;30(1):81-7. http://dx.doi.org/10.1093/humrep/deu272. PMid:25362088.

20. Liebaers I, Desmyttere S, Verpoest W, De Rycke M, Staessen C, Sermon K, et al. Report on a consecutive series of 581 children born after blastomere biopsy for preimplantation genetic diagnosis. Hum Reprod. 2010;25(1):275-82. http://dx.doi.org/10.1093/ humrep/dep298. PMid:19713301.

21. Kaur P, Swarankar ML, Maheshwari M, Acharya V. A comparative study between cleavage stage embryo transfer at day 3 and blastocyst stage transfer at day 5 in in-vitro fertilization/intra-cytoplasmic sperm injection on clinical pregnancy rates. $J$ Hum Reprod Sci. 2014;7(3):194-7. http://dx.doi.org/10.4103/0974-1208.142481. PMid:25395745.

22. Santos MJ, Arroyo G, Busquet A, Calderón G, Cuadros J, Mendoza MVH, et al. ASEBIR interest Group in Embryology. A multicenter prospective study to assess the effect of early cleavage on embryo quality, implantation, and live-birth rate. Fertil Steril. 2014;101(4):981-7. http://dx.doi.org/10.1016/j.fertnstert.2013.12.043. PMid:24502893.

23. Cissen M, Bensdorp A, Cohlen BJ, Repping S, de Bruin JP, van Wely M. Assisted reproductive technologies for male subfertility. Cochrane Database Syst Rev. 2016;2:CD000360. PMid:26915339.

\author{
*Correspondence \\ Rodrigo Dias Nunes \\ Universidade do Sul de Santa Catarina (UNISUL), Curso de Graduação em Medicina, Palhoça, SC, Brasil \\ Av. Pedra Branca, 25, Pedra Branca \\ CEP 88137-270, Palhoça, SC, Brasil \\ Tel.: +55 (48) 9932-9727 \\ E-mail: rodrigo.dias.nunes@hotmail.com
}

\title{
Author information
}

RDN - MsC in Health Sciences from the Post-Graduate Program in Health Sciences, Universidade do Sul de Santa Catarina (UNISUL); Professor at the School of Medicine, Universidade do Sul de Santa Catarina (UNISUL). TBFV - MD from at the School of Medicine, Universidade do Sul de Santa Catarina (UNISUL). JT - PhD in Health Sciences from the Post-Graduate Program in Health Sciences, Universidade do Sul de Santa Catarina (UNISUL); Professor at the School of Medicine, Universidade do Sul de Santa Catarina (UNISUL)

\section{Author contributions}

RDN participated in the conceptual elaboration, project development, data analysis and writing. TBFV participated in the project development and data collection. JT participated in data analysis, structuring of information and correction of the final text.- 